\title{
Nutritional factors in blood-cell formation
}

\author{
By Ronald H. Girdwood, Department of Medicine, University of Edinburgh
}

In recent years our knowledge of the formation, nutrition and metabolism of the cells of the blood has been greatly advanced by studies with the electron microscope, from tagging various nutrients and precursors with radioactive tracers, by advances in staining methods, by the use of specific enzymes to attack substances in particular regions of cells and of absorption-spectra techniques and various other new methods.

\section{Electron microscope studies}

Reference has already been made in this symposium to the picture of the cell as revealed by the electron microscope (Davidson, 1960); particular points about the structure of cells of haematopoietic tissue studied in this way have been made by Pease (1956) and by Ham (1957). The haemocytoblast has large nucleolar masses, large mitochondria, a well-developed Golgi apparatus, and numerous, diffusely scattered ribonucleic acid (RNA) granules. In the later forms of red-cell precursors the nucleoli become lost, the Golgi apparatus and endoplasmic reticulum disappear, the mitochondria are less numerous, and amorphous material, believed to be haemoglobin or its precursor, appears throughout the cytoplasm and nucleoplasm. RNA granules are seen until the cell is mature. Muir \& Kerr (1958) believe that the nucleus disintegrates without being extruded from the cell, but many workers do not share this view.

Apart from the appearance in the cell of the specific granules which appear to be inclusions formed in vesicles derived from the endoplasmic reticulum, there is little that need be said about the developing granular leucocytes. Ham (1957) suggests that, as they consist almost entirely of a nucleus, the lymphocytes may have a nutritive role in providing deoxyribonucleic acid (DNA) or DNA building blocks for other cells. They probably have only a short life in the blood stream in the course of their journey to the tissues. There is little to be said about the structure of monocytes that is relevant to the subject we are discussing, and plasma cells are seen to have an extraordinary development of the endoplasmic reticulum, arranged in anastomosing lamellae. In these cells there are many RNA granules and they tend to cover the surface of the endoplasmic reticulum. These features are shown in Pl. I. Platelets are formed from the cytoplasm of megakaryocytes and have a clear part, the hyalomere, and a coloured part, the chromatomere; the latter has mitochondria, distended membranous vesicles, specific granules and some RNA granules.

\section{Nutritional deficiencies that may affect the blood cells}

It is difficult to define what is meant by nutritional factors in relation to the blood cells. Many factors that influence development at the cellular level would not be considered by the clinician to be truly nutritional. Clinically, nutritional deficiency primarily affects erythropoiesis, although in some instances, such as vitamin $B_{12}$ depletion, there is an associated lowering of the white-cell and platelet counts. 
Bleeding diseases may occur from deficiency of vitamin $\mathrm{K}$, ascorbic acid and other factors, but the haemorrhagic tendency is not then due to interference with bloodcell formation.

The main groups of the anaemias are as shown in Fig. I.

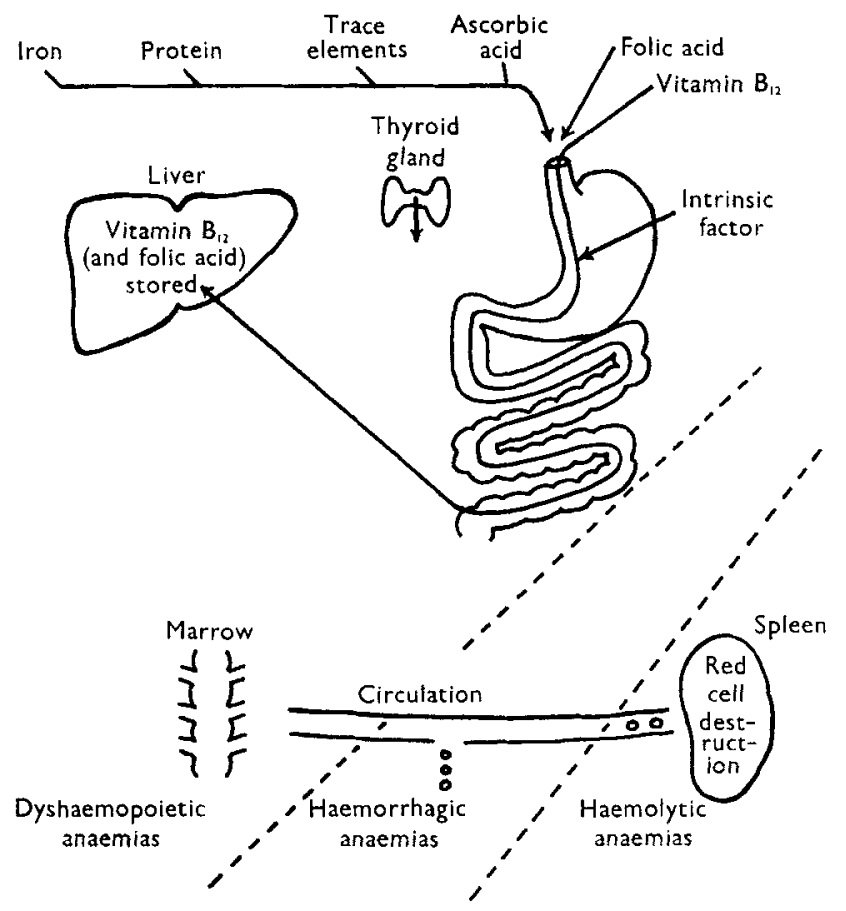

Fig. I. Types of anaemia.

It will be seen that, broadly speaking, the anaemias may be dyshaemopoietic, haemorrhagic or haemolytic, and at first sight our attention might be limited to the first of these main groups in which the anaemia may be due to nutritional deficiencies, malabsorption, impaired utilization, liver disease and aplasia or infiltration of the bone marrow. We need not, however, remain so limited in our outlook. Wintrobe (1956) has given a list of eighty-eight substances found in the human red-blood corpuscle, grouped under the main headings of protein, lipid, glycolytic system, enzymes, compounds related to haemoglobin, elements, vitamins and coenzymes. Of these, haemoglobin, which constitutes about $95 \%$ of the dry substance of the cell, may fittingly be considered first.

\section{The formation of haemoglobin}

Investigations by Thorell (1947) using absorption-spectra techniques have shown the rapid development of haem at the polychromatic normoblast stage. Thorell considered that globin might be formed earlier and haem then added to it, but studies involving the use of $\left[2^{-14} \mathrm{C}\right]$ glycine, carried out by Muir, Neuberger \& Peronne 
(I952) and by Kruh \& Borsook (1956) suggest that synthesis of haem and globin is simultaneous, unless another protein is first formed and later transformed into globin. The haem is on the surface of globin as four small prosthetic groups of haem molecules. Each of them consists of an atom of iron in the ferrous form co-ordinatively held by protoporphyrin. The naturally occurring haem is designated ironprotoporphyrin IX, and protoporphyrin IX consists of four pyrrole rings attached to each other by $-\mathrm{CH}=$ bridges. The problem of the biosynthesis of haemoglobin is a complex one that has recently been discussed by Rimington (1959). It seems that $\delta$-aminolaevulic acid is formed from succinate and glycine in the presence of coenzyme $A$, pyridoxal phosphate and ferrous ions. Two molecules of $\delta$-aminolaevulic acid condense to form porphobilinogen, from which is derived uroporphyrinogen III, then coproporphyrinogen III and finally protoporphyrinogen. Protoporphyrinogen, or more likely protoporphyrin derived from its reduced precursor, reacts with iron to give haem. The iron is hexacovalent, and in the plane of the flat porphyrin ring it links up with four $\mathrm{N}$ atoms. It can then bind one atom or atom group below the plane of the ring and one above this plane. When the band below the plane of the ring is attached to a certain group in the globin molecule the remaining co-ordination valence above the plane of the ring can attach itself reversibly to oxygen, and in this way the transport of oxygen takes place.

Iron is absorbed from the alimentary tract in the ferrous form, but it is stored in the spleen, liver, and bone marrow as ferritin, a protein that contains over $20 \%$ by dry weight of iron, the iron being ferric. The iron is in the centre of the protein as ferric hydroxide phosphate (Kerr \& Muir, 1960). Electron microscope studies by Bessis \& Breton-Gorius (1957a-c) have shown that red cells at the end of their life span are phagocytosed by reticulum cells and then digested. Small granules of ferritin then appear in the reticulum cells, increase in number, and scatter through the cytoplasm. Through a mechanism similar to pinocytosis (an invaginating and engulfing mechanism of the cell membrane), the ferruginous granules pass from the reticulum cells into young erythroblasts which are in close proximity in the marrow. In the red-cell precursors the ferritin molecules enter the mitochondria, then disperse and change into much finer granules. At this stage the mitochondria burst and the granules scatter in the cytoplasm to take their part in haemoglobin formation.

Goldberg (I959) has shown that reducing substances such as ascorbic acid, glutathione and ergothioneine in concentrations similar to those present in red cells increase enzymic protohaem formation in systems to which iron has been added in the ferric form, so that the necessary factors are then present for the final stage of the synthesis of haem.

\section{Abnormalities of haemoglobin formation}

It is perhaps convenient at this stage to mention certain abnormalities of haemoglobin formation. The siderocyte is a red cell that can be seen under the light microscope to have iron-staining granules in it. These are granules of haemosideriniron taken into the erythroblast, but not used for haemoglobin formation. Normally only a few siderocytes are found in the blood, but in some forms of haemolytic 
anaemia the majority of red cells may contain iron granules of this type. In thalassaemia, there are hypochromic red cells containing haemosiderin-iron which they cannot utilize to form haemoglobin.

The haemoglobin molecule is composed of two equal parts (Ingram, 1959), and in each half molecule there are two different peptide chains, called the $\alpha$ chain and the $\beta$ chain (Rhinesmith, Schroeder \& Pauling, I957). In the half molecule there are about 300 amino acids. Two genes which may or may not be on the same chromosome appear to be involved in the determination of the amino-acid sequence of the corresponding polypeptide chain, and if a chemical alteration occurs in a gene (that is, a mutation) there occurs also a chemical change in the polypeptide chain. This change means an amino-acid substitution in the haemoglobin structure, and so we find that a number of abnormal haemoglobins occur in man and in certain animals, and they are passed from generation to generation. Such abnormalities frequently lead to haemolytic anaemia, giving us a variety of haemoglobinopathies, the best known of which is sickle-cell anaemia. In thalassaemia, foetal haemoglobin (which has a different amino-acid composition from adult haemoglobin) persists into adult life, and anaemia may be associated. At the same time, other genetically determined abnormalities are present in the red cells in this condition (Hoffman, Wolman, Hillier \& Parpart, 1956). We do not yet understand the genetic pattern for the production of foetal haemoglobin and its normal replacement by adult haemoglobin.

Owing to limitations of space, I shall not deal with congenital methaemoglobinaemia, in which there appears to be an imperfectly functioning mechanism to reduce the ferric porphyrin complex to the ferrous form, or with porphyria, in which pigment metabolism is disordered.

\section{Deficiency anaemias}

Iron. In this country, the commonest type of anaemia is that due to iron deficiency, and it may be caused by inadequate intake of iron, malabsorption, increased demands, impaired utilization, loss of blood, or to a combination of these factors. Increased loss of iron from the body in sweat has been claimed to be an important factor in tropical countries (Foy \& Kondi, 1956).

Vitamin $B_{12}$ and folic acid. The second most common type of anaemia seen at blood clinics here is Addisonian pernicious anaemia, due to malabsorption of vitamin $B_{12}$ from lack of intrinsic-factor secretion by the stomach. Deficiency of vitamin $B_{12}$ or folic acid, or interference with the metabolism of the latter, leads to the appearance of an abnormal type of red-cell precursor, the megaloblast, in the marrow. Such deficiencies not only affect the development of the blood cells but interfere with many metabolic activities of the body. The functions of vitamin $B_{12}$ and folic acid have been considered elsewhere (Girdwood, 1959) but, briefly, an active substance derived from folic acid is concerned with the transfer of hydroxymethyl and formyl groups (and perhaps of formimino groups), whereas vitamin $\mathbf{B}_{12}$ appears to be concerned with the synthesis of methionine and choline-methyl groups. Where there is deficiency of vitamin $\mathrm{B}_{\mathbf{1 2}}$, as in untreated pernicious anaemia, a secondary deficiency of folic-acid substances may ensue. For instance, in the livers of 
five control patients without anaemia, malignancy or liver disease, I found the amounts of vitamin $\mathrm{B}_{12} / 100 \mathrm{~g}$ (fresh weight) to be $5^{\circ-150} \mu \mathrm{g}$ and of folic-acid substances to be $220-430 \mu \mathrm{g}$ expressed as folic acid. In three patients who died of untreated pernicious anaemia, the vitamin $B_{12}$ contents of the liver per roo $\mathrm{g}$ were respectively, none, $\mathrm{I} \cdot 6$ and $8 \cdot 5 \mu \mathrm{g}$, and the folic-acid activities were, respectively, 90,65 and $36 \mu \mathrm{g} / \mathrm{ro0} \mathrm{g}$.

It is well known that cobalt deficiency occurs in ruminants grazing on pastures with a low content of cobalt and that anaemia develops. The animals cannot synthesize cyanocobalamin in the rumen if there is cobalt deficiency. It is of interest that Andrews, Hart \& Stephenson (1958) working in New Zealand estimated the vitamin $B_{12}$ contents of the livers of groups of healthy and cobalt-deficient lambs, and found them to be: $39-$ I Io $\mu \mathrm{g} / \mathrm{IOO} \mathrm{g}$ (fresh weight) in healthy animals, $2.6-9.7 \mu \mathrm{g} / \mathrm{roO} \mathrm{g}$ when there was moderate to severe cobalt deficiency, and $0.8-6.8 \mu \mathrm{g} / \mathrm{ro0} \mathrm{g}$ when there was extreme deficiency. These results are very similar to the ones for human liver referred to above. The effects of cobalt deficiency in ruminants and the role of vitamin $\mathrm{B}_{12}$ in the metabolism of animals have recently been reviewed by Marston (1959). Reisner (1958) considers that where there is deficiency of folic acid or vitamin $\mathrm{B}_{12}$ the marrow becomes crowded with cells that are not able to synthesize enough DNA for division; if it is so, the failure of DNA formation may be due to a hold-up in the methylation of deoxyuridylic acid to thymidylic acid.

Elements other than iron. Anaemia due to deficiency of substances other than iron is rare in man. Thus, although copper deficiency leads to severe anaemia in most mammalian species, there has never been a proven case of anaemia due to copper deficiency in a human being, possibly because, apart from the fact that milk has a low content of copper, the element is widely distributed in foodstuffs and readily stored in the body. In man, cobalt deficiency does not lead to anaemia. On the other hand, the administration of cobalt increases the rate of erythropoiesis in man and experimental animals, and may lead to polycythaemia. This may be because cobalt ions stimulate the production of a humoral factor, erythropoietin (Jacobson, Goldwasser, Gurney, Fried \& Plzak, I959). However, Mirand, Prentice \& Slaunwhite (1959) consider that the polycythaemia produced in rats by cobalt chloride may not be due to increased amounts of erythropoietin. The latter substance is said to be a glycoprotein (Rambach, Cooper \& Alt, 1959) and it is believed to be produced in the kidney and perhaps in other sites.

Vitamins other than vitamin $B_{12}$ and folic acid. In scurvy one sometimes finds a normocytic type of anaemia that responds to treatment with ascorbic acid, but the picture is usually confused by deficiency of other nutrients, particularly of iron. Ascorbic acid is believed to act as a hydrogen donor in the formation of a metabolically active substance derived from pteroylglutamic acid. Brown (I955) has reported an instance of megaloblastic anaemia in scurvy that responded to ascorbic acid alone, but such an occurrence is unusual. Rare, too, are reports of anaemia in man due to lack of other vitamins. In animals, anaemia may develop from deficiency of riboflavin, nicotinic acid, or pyridoxine. In man there is no clear evidence that anaemia occurs from ariboflavinosis and, although normocytic, microcytic or even macrocytic 19 (1) 6 
anaemia may be found in pellagra, the nutritional deficiency is usually a multiple one and it may be complicated by hepatic cirrhosis. Foy \& Kondi (1958) have described a case of hypochromic anaemia that responded to treatment with pyridoxine. In this context it is of interest that in pyridoxine deficiency in animals there is a lymphopenia, and hence the pyridoxine antagonist deoxypyridoxine has been tried in the treatment of three cases of lymphosarcoma and four of acute lymphatic leukaemia (Gellhorn \& Jones, 1949; Weir \& Morningstar, 1954). In one of the patients with acute leukaemia there was a brief remission.

Protein. Although I have indicated some of the abnormalities of haemoglobin function, I have not so far made reference to anaemia from protein deficiency. Rimington (1959) has given a brief account of animal work on this aspect of nutritional problems, and indicates that the amount of haemoglobin synthesized to replenish a deficiency will be governed by the relative requirements and supply of essential amino acids, haemoglobin being built up from the common pool of amino acids in the tissues, or derived from the labile protein stores of the body. So far as man is concerned, anaemia due to protein deficiency alone is rare and not fully understood. Holmes, Stanier, Semambo \& Jones (195I), Stanier (I953) and Stanier \& Holmes (1954) found that in apparently normal Africans, there was a relationship between the red-cell count and the serum proteins, those with higher red-cell counts having higher albumin and lower globulin levels. Malnourished Africans had anaemia together with a low albumin level and an increase in $\gamma$-globulin. It was considered that this last was possibly due to increased protein synthesis by macrophages infiltrating the portal tracts of damaged livers. Woodruff (I955) considers that nutritional macrocytic anaemia in Nigeria is due largely to liver damage associated with protein malnutrition.

\section{Metabolism of glucose by red cells}

Red cells stored in acid-citrate-dextrose at $4^{\circ}$ begin to deteriorate after a few days, which is of great importance in relation to blood transfusions. The changes that occur include a decrease in the ability to metabolize glucose, loss of $\mathrm{K}^{+}$ions from within the cells and replacement by $\mathrm{Na}^{+}$, increased osmotic and mechanical fragility and diminished survival upon transfusion into a recipient. Methods of preservation of the cells include storage in glycerol at temperatures below $0^{\circ}$, and the addition of metabolic substrates or inhibitors. Gabrio, Finch \& Huennekens (1956) have found that adenosine will prolong the effective period of survival but consider that inosine would be better as it is less toxic on intravenous administration. Glucose is metabolized by glycolysis to give lactic acid, and this reaction is the major source of energy for the erythrocyte. Adenosine triphosphate (ATP) is required to prime this reaction and its amount diminishes with storage, with consequent cell deterioration. However, in the erythrocyte, glucose can be metabolized oxidatively via glucose-6-phosphate to 6-phosphogluconate, and if adenosine is metabolized by the shunt mechanism, no ATP is required initially, but synthesis of ATP occurs. In this way red-cell survival is prolonged. 
It may be mentioned here that in certain forms of haemolytic anaemia due to sensitivity to such agents as primaquine, sulphonamides or the broad bean (Vicia $f a b a)$, there is a low level of reduced glutathione (GSH) in the red cells, and it appears to be secondary to a genetically determined deficiency of glucose-6-phosphate dehydrogenase. The reactions are probably linked as follows (Prankerd, 1959):

$$
\begin{aligned}
& \text { Glucose-6-phosphate }+\mathrm{TPN}^{*} \rightleftharpoons \begin{array}{c}
\text { glucose 6-phosphate } \\
\text { dehydrogenase } \\
\text { glutathione } \\
\text { reductase }
\end{array} \\
& \begin{array}{l}
\text { Glutathione disulphide }(\mathrm{GSSG}) \rightleftharpoons \mathrm{TPNH}+\mathrm{H}^{*}+\mathrm{H}^{+} \\
+ \text {TPNH }+\mathrm{H}^{+}
\end{array}
\end{aligned}
$$

Recently, too, Jocelyn (I 959), following up the work of Ling \& Chow (1953) and Register (I954), who reported a low level of $\mathrm{GSH}$ in vitamin $\mathrm{B}_{12}$-deficient rats or patients with pernicious anaemia, has found that in one of three cases of untreated pernicious anaemia, a severe case, there was a raised level of GSSG in the red cells, which became normal on treatment with cyanocobalamin. This finding suggests that vitamin $B_{12}$ is involved in the reduction of GSSG in human erythrocytes.

\section{Nutrition of isolated bone marrow}

Quite recently much interest has been aroused in relation to bone-marrow culture and transplantation. The problems of bone-marrow culture have recently been reviewed by Reisner (I959), and Thomas \& Lochte (1957) have shown in vitro that normal serum is required to ensure a rapid rate of DNA synthesis by bone-marrow cells. The latter workers use an estimation of the incorporation of $\left[{ }^{14} \mathrm{C}\right]$ formate into thymine as an indication of the extent of DNA synthesis by these cells. They consider that the rate of DNA synthesis measured in this way gives an indication of cell viability. Human bone marrow collected from foetal or adult cadavers or from biopsy or surgical specimens can be preserved in glycerol at $-80^{\circ}$ for several weeks and then given intravenously, for instance to a heavily irradiated leukaemic subject ('Thomas, Lochte, Lu \& Ferrebee, I957). The administered cells can survive and grow, and much interest has been aroused about the possible applications of such heroic methods of therapy.

\section{Conclusion}

It has been possible to refer only briefly to certain features of the nutrition of the blood cells; space does not permit consideration of many related matters of interest, particularly of those chemical agents that interfere with nucleic-acid metabolism and hence are used in the treatment of leukaemia. This, however, is a large subject in itself, and it might be considered sufficiently nutritional to be suitable for another symposium of this Society.

* TPN, oxidized and TPNH, reduced triphosphopyridine nucleotide. 


\section{REFERENCES}

Andrews, E. D., Hart, L. I. \& Stephenson, B. J. (1958). Nature, Lond., 182, 869.

Bessis, M. C. \& Breton-Gorius, J. (r957a). F. biophys. biochem. Cytol. 3, 503.

Bessis, M. C. \& Breton-Gorius, J. (1957b). Bull. Micr. appl. 7, 54.

Bessis, M. C. \& Breton-Gorius, J. (1957c). C.R. Acad. Sci., Paris, 244, 2846.

Brown, A. (1955), Brit. Y. Haemat. I, 345.

Davidson, J. N. (1960). Proc. Nutr. Soc. 19, 38.

Foy, H. \& Kondi, A. (1956). Lancet, 270, 423 .

Foy, H. \& Kondi, A. (1958). Blood, 13, 1054.

Gabrio, B. W., Finch, C. A. \& Huennekens, F. M. (1956). Blood, rr, 103.

Gelihorn, A. \& Jones, L. O. (I949). Blood, 4, 60.

Girdwood, R. H. (r959). Scot. med. F. 4, 300.

Goldberg, A. (1959). Quoted by Rimington, C. (I959).

Ham, A. W. (1957). Histology, 3rd ed. London: Pitman Medical Publishing Company Ltd.

Hoffman, J. F., Wolman, I. J., Hillier, J. \& Parpart, A. K. (r956). Blood, rr, 946.

Holmes, E. A., Stanier, M. W., Semambo, F. B. \& Jones, E. R. (I95I). Trans. R. Soc. trop. Med. Hyg. $45,37 \mathrm{I}$.

Ingram, V. M. (1959). Brit. med. Bull. 15, 27.

Jacobson, L. O., Goldwasser, E., Gurney, C. W., Fried, W. \& Plzak, L. (r959). Ann. N.Y. Acad. Sci. $77,55 \mathrm{I}$.

Jacelyn, P. C. (1959). Biochem. Y. 72, I IP.

Kerr, D. N. S. \& Muir, A. R. (1960). F. ultrastruct. Res. (In the Press.)

Kruh, J. \& Borsook, H. (1956). F. biol. Chem. 220, 905.

Ling, C. T. \& Chow, B. F. (1953). F. biol. Chem. 202, 445 .

Marston, H. R. (1959). Med. F. Aust. ii, 105.

Mirand, E. A., Prentice, T. C. \& Slaunwhite, W. R. (1959). Ann. N.Y. Acad. Sci. 77, 677.

Muir, A. R. \& Kerr, D. N. S. (1958). Quart. F. exp. Physiol. 43, 106.

Muir, H. M., Neuberger, A. \& Peronne, J. C. (1952). Biochem. F. 52, 87.

Pease, D. C. (1956). Blood, Ix, 501.

Prankerd, T. A. J. (1959). Brit. med. Bull. 15, 54.

Rambach, W. A., Cooper, J. A. D. \& Alt, H. L. (1959). Ann. N.Y, Acad. Sci. 77, 623.

Register, U. D. (1954). F. biol. Chem. 206, 705.

Reisner, E. H. (1958). Blood, 13, 313.

Reisner, E. H. (1959). Ann. N.Y. Acad. Sci. 77, 487.

Rhinesmith, H. S., Schroeder, W. A. \& Pauling, L. (1957). F. Amer. chem. Soc. 79, 4682.

Rimington, C. (1959). Brit. med. Bull. I5, I9.

Stanier, M. W. (1953). Nature, Lond., 171, 880.

Stanier, M. W. \& Holmes, E. G. (1954). Brit. F. Nutr. 8, 155.

Thomas, E. D. \& Lochte, H. L. (1957). Blood, r2, I086.

Thomas, E. D., Lochte, H. L., Lu, W. C. \& Ferrebee, J. W. (1957). Nerw Engl. F. Med. 257, 49 I.

Thorell, B. (1947). Acta. med. scand. Suppl, 200.

Weir, D. R. \& Morningstar, W. A. (1954). Blood, 9, 173.

Wintrobe, M. W. (1956). Clinical Hematology, 4th ed. London: Henry Kimpton.

Woodruff, A. W. (1955). Brit. med. F. i, 1297.

\section{EXPLANATION OF PLATE}

Electron-microscope picture of a rat-plasma cell. (By courtesy of Dr A. R. Muir, Department of Anatomy, University of Edinburgh.) 


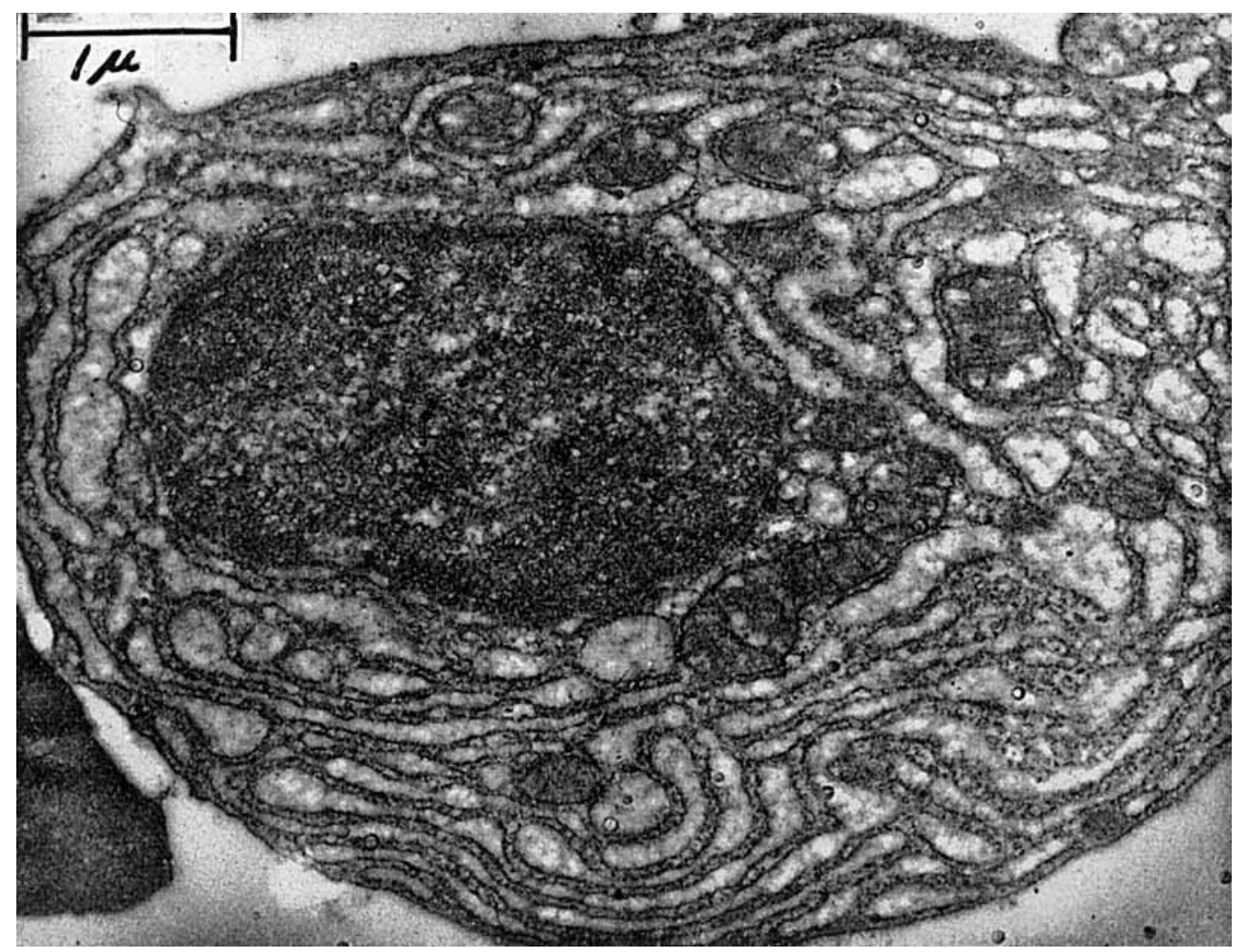

Proceedings of The Nutrition Society, Vol. I9, No. I 